\title{
The Transformation of Burnet's Immune Surveillance Cells into Natural Killer Cells and its Circumstances
}

\section{Joseph Geza Sinkovics ${ }^{1^{*}}$ and Joseph Csaba Horvath ${ }^{2}$}

${ }^{1}$ Retired Medical Director, The Cancer Institute, St. Joseph's Hospital, Tampa FL, USA

${ }^{2}$ Retired Director of Research \& Development, Hemispherx Biopharma, Inc., New Brunswick, NJ, USA

*Corresponding author: Joseph Geza Sinkovics, Retired Medical Director, the Cancer Institute, St. Joseph's Hospital, Tampa FL, USA

\section{Introduction}

In 1969 it was very difficult to explain the sudden unexpected appearance of some finely granulated large lymphoid cells that had been hidden in the human blood for over a full century, as they suddenly revealed themselves in our laboratory at M.D. Anderson Hospital, Houston TX. At first, the hematopathologists considered these cells to be of monocytoid (M) derivation;

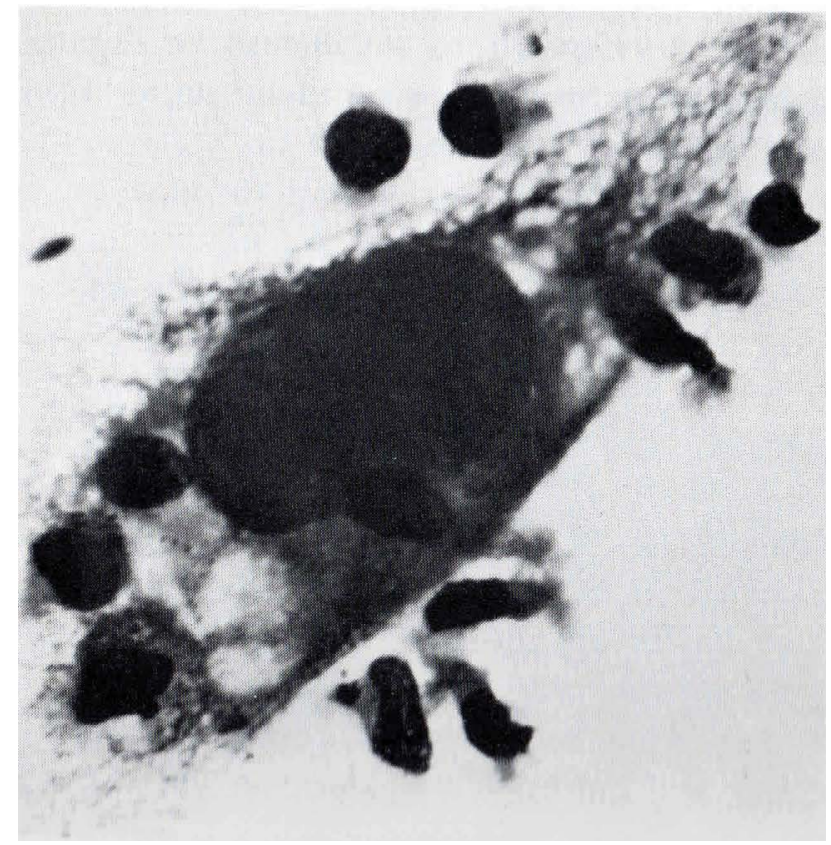

Figure 1: Human fibroblast-like cell surrounded by small elongated immune T cells. by accidental misprint, instead of monocytoid noted as "macrophagic" in the legends. These new cells appeared clearly distinct from the already well known compact $T$ cells (Figure 1), as a different new population (Figure 2), since their cytoplasm displayed fine round unstained white granulation. These larger rounded up lymphoid cells were cytotoxic to tumor cells; compare with hundreds of detailed complex pictures produced in the following years. This chapter also showed the tetraploid fused cells that have become later the first "hybridomata", natural or artificially produced. The large granulated lymphoid cells we soon referred to as "Burnet's Immune Surveillance Cells" and held them

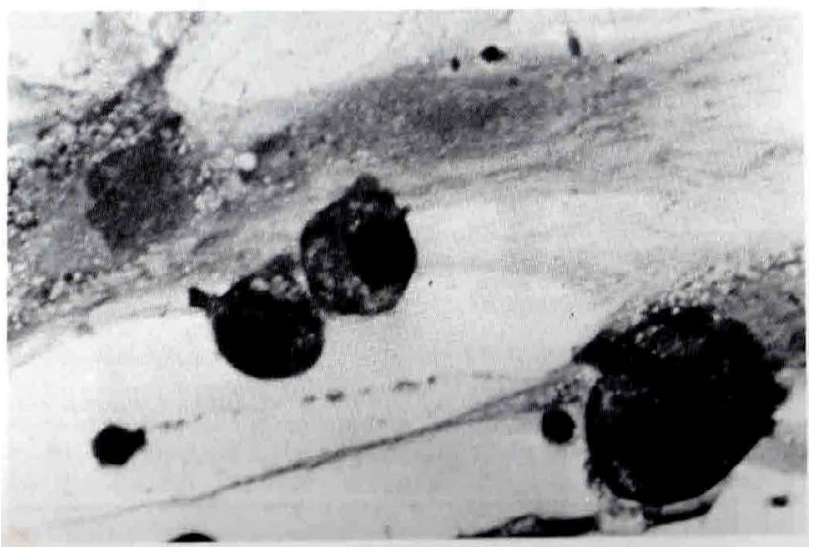

Figure 2: Unidentified human large mononuclear cells appear between human sarcoma cells showing small round unstained cytoplasmic granules. First referred to as "Burnet's immune surveillance cells" (1969); later (1975) re-discovered as "natural killer cells". 


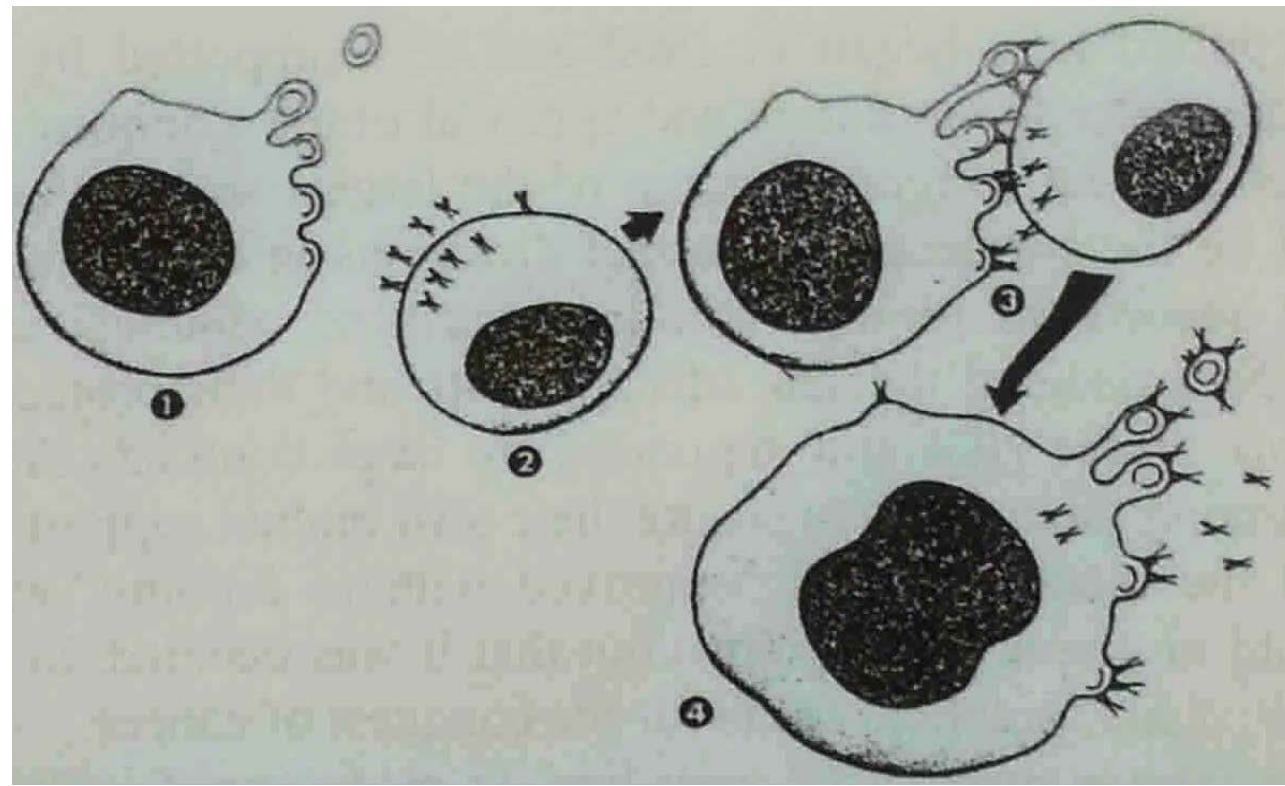

Figure 3: First depiction of diploid murine malignant lymphoma cell with budding retrovirus particles fusing with immune plasma cell of its host producing specific antiviral immune globulins much later referred to as a tetraploid "hybridoma" [2-4]. Figures 1, 2, 3 cited from Leukemia-Lymphoma A Collection of Papers Presented at the Fourteenth Annual Clinical Conference on Cancer, 1969 at The University of Texas M.D. Anderson Hospital and Tumor Institute at Houston. Houston, Texas. YEAR BOOK MEDICAL PUBLISHERS, INC. CHICAGO.
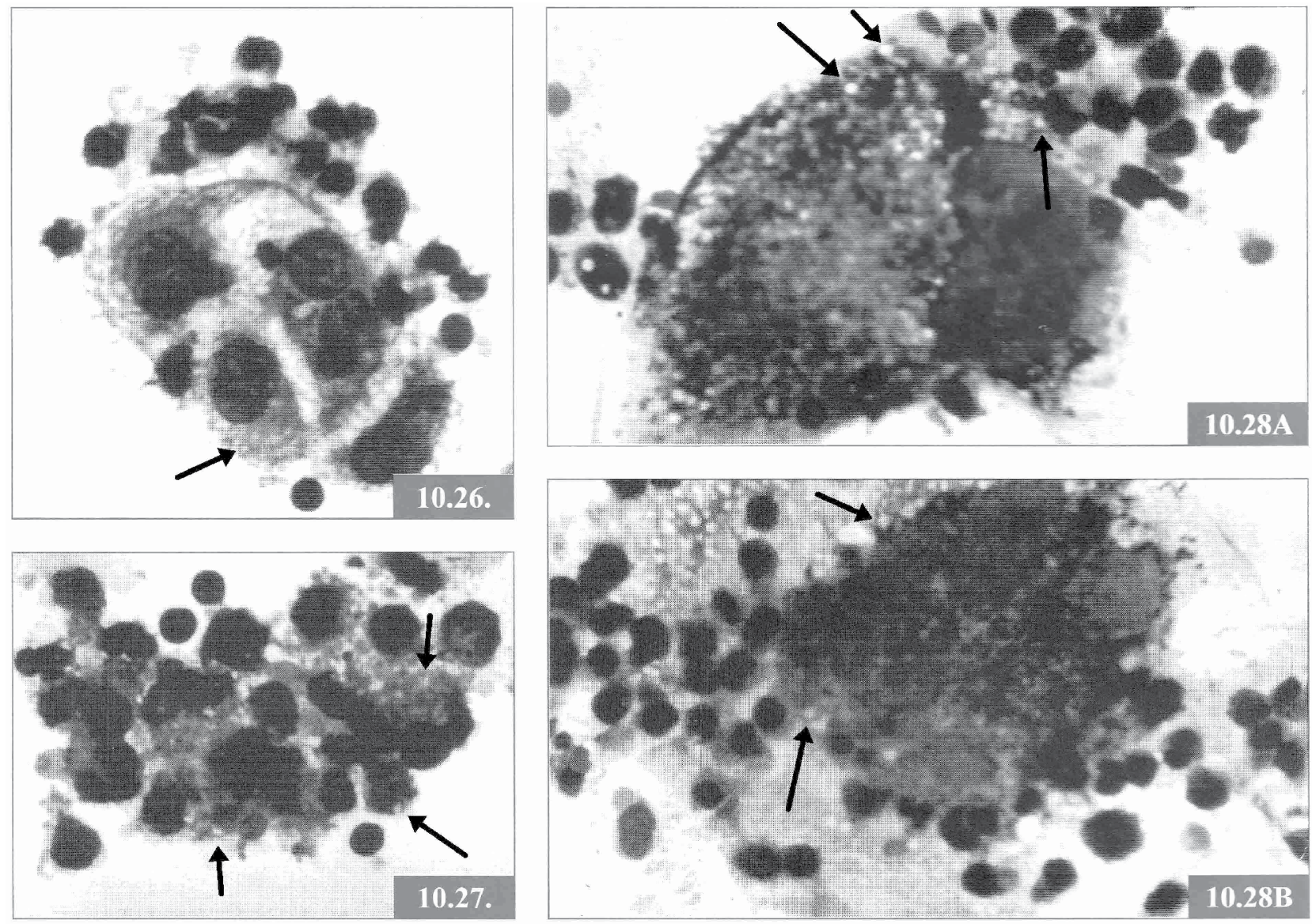

Figure 4: Original figure preserved from 1973 in the remnants of the Sinkovics Laboratory [1-4]. The reproduction of figures $10.26,10.27$ and 10.28AB from page 124 of reference [3] shows lymphocytic infiltrates of human tumors (kidney carcinoma, malignant melanoma and rhabdomyosarcoma) from the early 1970s in the Sinkovics Laboratory at MD Anderson Hospital. The lymphocytic infiltrates included the well-known compact immune $T$ cells and the recently recognized large granular lymphoid cells ("Burnet's immune surveillance cells", later NK cells). These latter cells (the NK cells) but not the T cells, in their cytoplasm and extracellularly spaces contain numerous unstained small round white granules singly or in groups [3] that were later recognized elsewhere as the azurophilic enzymes of the NK cells [6]. 
identical by 1975 to the "Natural Killer Cells" of the Herberman's and Kleins'. Shown in the same original article, were indirect fluorescent antibody-stained preparations in search of "tumor antigens". This heavily overweight presentation forecasts the massive basic developments of tumor immunology to follow, in which malignant lymphoblasts fusing with immune plasma cells and forming hybridomata have become eventually the source of potentially curative monoclonal antibodies (Figure 3) (Sinkovics JG, Shirato E, Gyorkey F, Cabiness JR, Howe CD in "Leukemia-Lymphoma" at The University of Texas MD Anderson Hospital and Tumor Institute, Houston TX. Year Book Medical Publishers Pp 53-92 1970).

\section{The Subject Matter}

This Letter to the Editor is intended to be a continuation of the senior author's reminiscence recently published in the Journal [1]. That was the era of searching for the most effective immunotherapeutic modality offering itself for the potential cure of the advanced human cancer that continued to relapse against toxic, even carcinogenic combination chemo-radiotherapy regimens. Vaccinations with viral oncolysates, stimulation of dendritic cells and passive transfer of monoclonal antibodies continued to induce remissions that still ended in relapses. It has become resounding medical history that checkpoint control with ipilimumab (of James Allison), pembrolizumab (of Tasuku Honjo) and related monoclonal antibodies achieved the durable complete remissions that persisted without relapse up to half of the treated patients; partial remissions were substantially prolonged. Achieving cures regularly (not anymore only occasionally) in metastatic human cancers has now been accomplished. Independently emerged the "Burnet's Immune Surveillance Cells" or "Natural Killer Cells" that were discovered twice, first at the University of Texas MD Anderson Hospital in Houston TX in the late 1960s and at the Karolinska Institute in the mid-1970s (Rolf Kiessling, Eva Klein, et al.). This latter discovery was shared with a contemporaneous achievement of similar results at the National Cancer Institute, Bethesda MD by Ronald Herberman, et al. Thereafter, these latter two institutions (the Kleins, Petter Höglund; Ronald Herberman, et al.) accepted each other as co-discoverers, and obligatorily cross-referenced each other. Unfortunately, all other references to NK cells, especially concerning that one made originally and much earlier at MD Anderson [2-4] were left out. Those earlier publications [2-4] were never disqualified in any debates or open criticism but were simply omitted of all citations in the literature, as if non-existent.

These larger lymphoid cells ("Burnet's Immune Surveillance Cells" in the Sinkovics' Lab; "Natural Killer Cells" in the Kleins' and Herberman's Lab) morphologically and evolutionally differed from the smaller compact immune $T$ cells that were cultured previously world-wide from the 1950s on (Ronald Herberman
Editor, National Cancer Institute Monograph 37, 1973; Marshall A. Lichtman [5]). Extensive literature showed murine and human cultures of these small compact $T$ lymphocytes originally and prominently carried by Karl Erik and Ingegerd Hellström, et al. and Farkas Vánky and Eva Klein, et al. at the Karolinska Institute in Stockholm Sweden (thus they are extensively cited so [2-4]). Not these compact immune T cells, but morphologically and biochemically different much larger granular lymphocytes re-appearing again in 1975 and thereafter in murine and in human hosts were designated as "Natural Killer NK Cells" by Rolf Kiessling, Eva Klein, et al. at the Karolinska Institute, and Ronald Herberman, et al. at the National Cancer Institute, Bethesda Maryland, and comprehensively so cross-cited by these authors $[6,7]$. The Rolstad article expresses gratitude for Höglund's editorial guidance (Sinkovics omitted) [6,7]. Originally, these large lymphoid cells, more than twice the size of the well known compact immune T cells, could show in Giemsa- or Wright-stained preparations their minuscule small cytoplasmic granulations in white, when remaining unstained (Figure 4). First, electron microscopy confirmed the presence of minuscule cytoplasmic granules in these large lymphoid cells, as they were released and thus rendered their attack upon their targeted tumor cells [2]. The cytoplasm of the NK cells in its diffuse pale bluish coloration, revealed the presence of minuscule white unstained granules in clumps both in extra- and intracellular existence (arrows in Figure 4). Figure 5 compares in color the morphology of the compact human immune $T$ cells on one side, and that of the large NK cells on the other side of a large human tumor (sarcoma) cell, as this latter entity (the NK cell) releases its granules to react with the targeted tumor cell in order to lyse it. The event shown here occurred in one

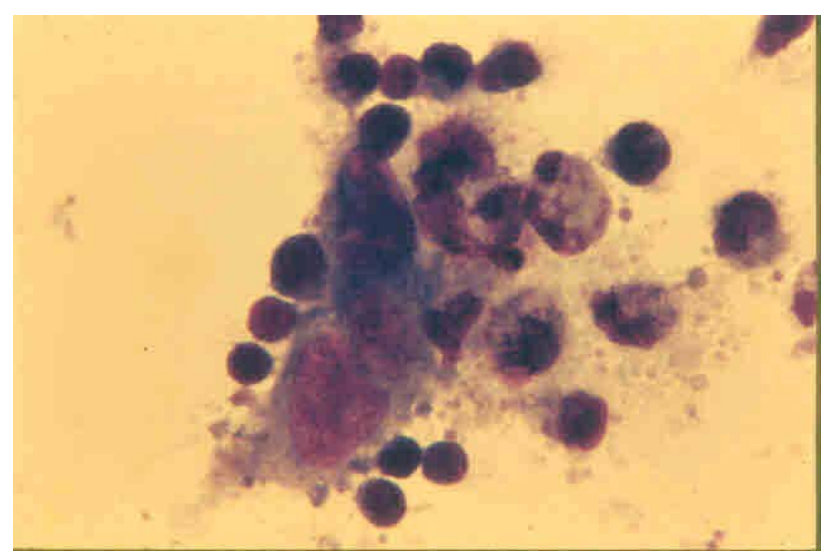

Figure 5: Reproduced from the Sinkovics Laboratory at MD Anderson Hospital in the 1970s [1-4]. A cell of the established sarcoma cell culture line \#3743 that yielded the live PR8 viral oncolysate vaccine is attacked by small compact T lymphocytes and large granular Burnet's immune surveillance cells (NK cells) in MD Anderson Hospital male patient LN \#90641 with metastatic liposarcoma in remission [8,9]. The large granular lymphoid cells of the immunized patient release their minuscule granules that penetrate and lyse the targeted sarcoma cell of established \#3743 cell line. 
long term survivor male patient with metastatic liposarcoma in remission (LN at MDAH \#90641), who was attended by the team of this senior author $[3,4]$, as repeatedly shown in appreciation for its value [1,3]. Thereafter, the authors R Herberman, B Rolstad, P Höglund and the Kleins extensively cited their own and each others references, while meticulously omitting any citations to prior publications of Sinkovics, et al. [6,7]. Thus, the original concept of "Burnet's Immune Surveillance Cells" was successfully erased from the literature; there remained the Natural Killer Cells, whose reign was shown to have originated not in the late 1960s in the Sinkovics' Lab but in the Herberman's and Kleins' Labs (however, some 5 years later) [7].

\section{Past Tense}

Two different unexpected new phenomena emerged in the Sinkovics Laboratory at the Department of Medicine MD Anderson Hospital in the late 1960s [1$4,8,9]$. These involved mouse (murine) and human lymphocytes. In the diploid mouse lymphoma cells budding retrovirus particles appeared. These lymphoma cells "spontaneously" fused with immune plasma cells producers of immunoglobulins specifically reactive to the budding retrovirus particles, thus, these two cells fused spontaneously forming tetraploid cells. These tetraploid cells were recognized as the first natural hybridomas in existence. When artificially duplicated, they produced diagnostic and therapeutic monoclonal antibodies that won the Nobel Prize, without citing their predecessor, the first natural hybridoma of Sinkovics (vide supra). For that, Sinkovics received the Hațieganu University's award "Out-Nobel" in Cluj Napoca, Romania. The antibody-coated tetraploid fused cells were lysed by macrophages, thus forming the classical morphology of the "starry sky" phenomenon [3,4], imitating those appearing in Burkitt's lymphoma.

In human subjects, two types of lymphoid cells cytotoxic to malignantly transformed tumor cells emerged. First, the already well known immune $T$ cells (the Hellströms; F Vánky and Eva Klein, vide supra) appeared reacting to and killing malignantly transformed cells by apoptosis. Second, never seen before large diploid cells released a cloud of minuscule granules causing cytoplasmic lysis of their targeted malignantly transformed cells, and so attacked and killed tumor cells (Figure 5). Our team (H David Kay, Harikishan Thota, C Charles Shullenberger, Clifton D Howe, and Joseph Sinkovics immediately, and later Joseph C Horvath $[3,4]$, referred to these newly appearing lymphoid cells as the representatives of the much awaited and highly expected "Burnet's Immune Surveillance Cells". Eiichi Shirato photographed scenes of immunofluorescence involving these cells interacting with one another as they produced granzyme-related cytolysins [3].

Investigational trials in cooperation with the University of South Florida associate professor and St. Joseph's
Hospital's research laboratory leader Joseph C Horvath were confined to consenting single adult patients, whose lymphoid cells were subjected to in vitro trials without clinical involvement of the patient [10-12].

Credit received from Lara Marks on the What Is Biotechnology? internet platform (https://www.whatisbiotechnology.org/index.php/people/summary/Sinkovics), then from Wainwright for the first original discovery of natural hybridoma formation [13], that in theory (and practice) we expand from the murine to the human host [14].

\section{Final Comment}

MD Anderson's clinical professor of hematology Charles C Shullenberger in good will upon the recognition of retroviral etiology for murine leukemias directed some of those first articles to the realm of experimental basic sciences away from that of the clinical human hematology literature. Thus, murine leukemias were viewed (and still are) of a unique etiology and immunobiology of their own [15].

\section{Citations}

The retiring professor Marshall A Lichtman wrote: "In 1969 Joseph (József) Géza Sinkovics (b. 1924), a physician-scientist and Hungarian émigré, working in the section of Clinical Tumor Virology and Immunology at the MD Anderson Cancer Center, observed that his unprimed lymphocytes killed allogeneic tumor cells in vitro. He reported his findings shortly thereafter. He also showed that the cells involved in attaching to and lysing tumor cells were large granular lymphocytes. Although his report was met with skepticism and rejection (a project site visitor proclaimed "There is no immune reaction without preimmunization"), this work was confirmed and expanded to indicate that the unprimed lymphocytes also could kill virus-infected cells. In his monograph, Sinkovics reviewed the reaction of the scientific community to his finding that tumor reactive lymphoid cells might be present without preimmunization of their host. He provided the first photomicrographs and tumor cell growth inhibitory graphs describing such cells. At about the same time (1970), Sinkovics described a lymphoproliferative disease, which in retrospect may have had a natural killer cell phenotype" $[5,16]$.

\section{References}

1. Sinkovics JG (2019) The first human immunotherapy trial with a viral vaccine induced a large number of granular lymphocytes later recognized as "Natural Killer Cells". Internat J Virology AIDS 6: 49.

2. Sinkovics JG (2019) Large granular lymphoid cells discovered first in the human blood as "Burnet's Immune Surveillance Cells" (1969) are identical with the late-designation "Natural Killer Cells" (1975). Ann Clin Lab Sci 49: 691-698.

3. Sinkovics JG (2008) Cytolytic immune lymphocytes. Schenk verlag dialog campus, Budapest Passau, 391. 
4. Sinkovics JG, Horvath JC (2005) Human natural killer cells: A comprehensive review. Int J Oncol 27: 5-47.

5. Lichtman MA (2018) Historical landmarks in an understanding of the lymphomas. In: Wiernik PH, Neoplastic Diseases of the Blood. Springer International Publishing, 675-721.

6. Rolstad B (2014) The early days of NK cells: An example of how a phenomenon led to detection of a novel immune receptor system- lessons from a rat model. Front Immunol 5: 283.

7. Höglund P, Klein E (2006) Natural killer cells in cancer. Seminars Cancer Biology 16: 331-332.

8. Sinkovics JG, Plager CV, McMurtrey MJ, Romero JJ, Romsdahl MM (1977) Viral oncolysates for the immunotherapy of human tumors. Proc 68th Annual Meeting American Society Clinical Oncology Denver Colorado \#344 May 16-17.

9. Sinkovics JG, Plager C, Papadopoulos N, McMurtrey M, Romero JJ (1977) Immunology and immunotherapy of human sarcomas. In: Immunotherapy of Human Cancer. 22nd Annual Clinical Conference. The University of Texas MD Anderson Hospital and Tumor Institute. Raven Press, New York, 267-288.

10. Horvath JC, Sinkovics JG (2003) Human tumor antigens released in viral oncolysates are loaded onto dendritic cells. 94th Annual Meeting American Association Cancer Research Toronto Canada \#4762.
11. Horvath JC, Pritchard M, Vega V, Sinkovics JG (2003) The viral oncolysate story and its expansion toward dendritic cell vaccines. Symposium: "Oncolytic viruses as cancer vaccines" Banff Canada P 45: 26-30.

12. Horvath JC, Horvath E, Sinkovics JG, Horak A, Pendleton $S$, et al. (1998) Human melanoma cells (HMC) eliminate autologous host lymphocytes and escape apoptotic death by utilizing the FasL system as an autocrine growth loop. Proc American Assoc Cancer Res 39: 584.

13. Wainwright M (1992) The Sinkovics Hybridoma - the discovery of the first "Natural Hybridoma". Perspectives Biology Medicine. Chicago Illinois Spring 35: 372-379.

14. Sinkovics JG (2016) RNA/DNA \& Cancer. Springer Verlag Pp 815 Heidelberg New York Dordrecht London.

15. Sinkovics JG, Groves FG, Bertin BA, Shullenberger CC (1969) A system of tissue cultures for the study of a mouse leukemia virus. J Infectious Diseases 119: 19-38.

16. Sinkovics JG, Thota H, Kay HD, Loh KK, Williams DE, et al. (1975) Intensification of immune reactions by immunotherapy: Attempts at measuring sarcoma-specific reactions in vitro. In: Ray Crispen, Neoplasm Immunity: Theory and Application. Proceedings of a Chicago Symposium, 137-152. 